\title{
Exploring digital literacy: How do undergraduate students evaluate digital video for inclusion in assignment work?
}

\author{
Peter Tiernan \\ peter.d.tiernan@dcu.ie \\ Dublin City University, Ireland
}

\begin{abstract}
In an effort to explore digital literacy in practice, this paper investigates how students evaluate digital video for use in assignment work. Students sourced content for a written assignment from a selection of videos housed on an online repository and reflected on their choices. The study examines the key areas influencing the use and evaluation of digital video for assignments such as digital literacy, the learning value of video, and strategies for integrating video. This paper examines students' experiences using video for assignment work and pays particular attention to their evaluation of video content and their reasons for selecting videos. Findings show that students select video based on its relevance to their existing knowledge, ability to develop their arguments, and on the source and quality of content. Students display key elements of digital literacy when provided with an authentic task, and the appropriate strategies and content to accomplish this. The work also presents a series of recommendations and considerations for future work in the area.
\end{abstract}

\section{Keywords}

digital literacy; media in education; online video 


\section{Introduction and context}

The prevalence of digital information and the level of interaction and engagement which take place online have increased interest at policy and academic levels in the ways in which students are able to process and interact with digital content. The popularity of online video in particular is well documented, with more than $82 \%$ of 18 - 29 year olds regularly visiting the online video sharing platform YouTube (Anderson 2015). Students in this age range feel that access to streaming video is as important as internet connectivity and email (Riismandel 2016). The purpose of this paper is to investigate how undergraduate students evaluate video for inclusion in a written assignment. In order to fully investigate this area, this study begins by examining a number of interrelated themes.

We have entered an information era where the internet and web technologies are where ideas meet and collaboration happens (Pérez-Escoda et al. 2019), transforming the way we work, learn, and express ourselves (List et al. 2020). In this context, digital literacy is recognised as an essential skill for living in the 21st century (Pérez-Escoda et al. 2019) and an essential capacity for lifelong learning (Rohatgi et al. 2016). Universities (E.g., University of South Australia 2015; Leeds Beckett University 2014; Open University 2012) have begun defining digital literacy as a core skill to be developed among their student population. Terms such as ICT literacy and computer literacy have existed since the 1970s (Martin 2005), focusing on the operational aspects of using technology for everyday tasks (Oliver et al. 2000), such as managing files and using word processing software. The term digital literacy was originally brought to prominence by Gilster (1997) who viewed it as "the ability to understand and use information in multiple formats from a wide range of sources when it is presented via computers" (p. 1), arguing that it is not simply about finding things online but more importantly, how to evaluate these things for use in your daily life. Since then, digital literacy has evolved as a concept, however there is relative congruence among authors around its core aspects. For example: Martin (2005) argued that digital literacy is about using digital tools to identify, evaluate, analyse, and synthesise digital resources; $\mathrm{Ng}$ (2012a) suggests it is the ability to search for, evaluate, understand, and integrate information found online; Kim (2019) defined it as the ability to use digital technologies to collect, analyse and evaluate information, as well as construct new information and communicate with others during the process; Churchill (2020) asserts it is the ability to search for and evaluate information using digital tools, then use this information to address an authentic problem. The ability to evaluate digital content is a crucial component of digital literacy, especially in the context of university learning. The JISC (2015) framework suggests that the evaluation of digital content comprises of a mix of information, data, and media literacy skills. It involves the interpretation of digital information for academic purposes, where learners review and evaluate content in terms of its quality, relevance, credibility, and usefulness for the task at hand. Similarly, the DigiComp framework (Vuorikari et al. 2016) proposes that learners should be able to filter through digital information by evaluating the content, before incorporating this data into their work. In Kurtz and Peled's (2016) seven domains of digital literacy, information evaluation is also defined in terms of evaluating the quality, relevance, and usefulness of digital resources. This study focuses specifically on analysing students' ability to evaluate and utilise digital video for a practical academic task.

We know from previous research that video has a broadly positive impact on the student learning experience (Nagy 2018; Ranga 2017) and can be successful in supporting traditional teaching practices (Bohloko et al. 2019). There are a number of specific ways in which video adds value to the learning experience. First, video can improve learner motivation and engagement (Koumi 2013). The multi-modal nature of video has the potential to hold student interest and attention (Choi and Johnson 2010; Meseguer-Martinez et al. 2017), stimulate multiple senses (Bower 2017), and develop an emotional connection with topics (Sweeney and Baker 2018). Second, video can add value by explaining processes, introducing real world examples, and providing demonstrations (Koumi 2013). Complex concepts can be viewed multiple times and sections can be repeated 
(Weeks and Horan 2013), ideas can be slowed down or sped up to improve understanding (Kettle 2020), skills can be witnessed rather than explained, and can be broken down step-by-step (Srinivasa et al. 2020). Third, video can add experiential value by showing or documenting phenomena that would otherwise be inaccessible (Koumi 2013). Natural and historical events can be accessed by students when they may otherwise remain hidden (Snelson 2008). Exposing students to alternative viewpoints and opinions can positively impact their thinking (Hakkarainen et al. 2007). Work completed by a wide range of authors (Dong and Goh 2015; Moskovich and Sharf 2012; Mitra et al. 2010; Berk 2009) suggests that realising the learning value of video involves linking video to authentic learning tasks where students' attention is guided towards specific aspects or themes. These tasks should involve reflection on video content, establishing links to current knowledge, and provide students with opportunities to integrate video content into their work.

This study aims to bridge a gap identified by authors such as Bhatt et al. (2015) and Churchill (2020) by capturing and analysing digital literacy in practice, while simultaneously deepening our understanding of how students evaluate video content for use in their academic work (Mitra et al. 2010).

\section{Methodology}

\section{a. Participants}

This study was conducted in the Institute of Education at Dublin City University. Participants $(n=66)$ were studying for a B.Sc. in Education and Training. The module being undertaken was 'Social and Personal Development with Communication Skills', which is delivered during semester one of first year. The aim of the module is to support independent learning, encourage social interaction, develop critical thinking and reflective skills, and help students to recognise their own strengths and weaknesses as they relate to academic life. Module topics included 'goal setting', 'time management', 'learning styles and learning strengths', creativity and creative thinking', 'communication skills', 'conflict management' and 'stress management'.

\section{b. Description of process}

Scholars have long argued that in order to gain a full understanding of what digital literacy means in practice, students should be guided through the completion of authentic academic tasks which involve the integration of digital media (Littlejohn et al. 2012; Margaryan et al. 2011; Buckingham 2007). With this in mind, students in this study were tasked with writing a 1,500-word paper discussing a number of different aspects of communication skills. The assignment required students to use video as a source of information for their work and provide reflective details on how they evaluated ( $\mathrm{Ng} \mathrm{2012a)}$ and filtered (Bawden 2001) this for inclusion. Students were tasked with discussing three elements of communication skills from a list of ten provided. Each essay was required to have a minimum of eight references, five of which were to be taken from the video content provided on an inhouse online repository. In order to reference video content, students were asked to provide the title of the video and the timestamp of the location of the specific section of the video they referenced. The repository contained a minimum of twenty relevant videos for each assignment topic heading and in fact a lot of crossover was evident within the videos, so that each topic had a depth and variety of content available for the students to choose from. The range of content included: University produced video; various TED talks; corporate training material; uploaded television content; YouTube channel content. Each video was first viewed in full to ensure the quality of the content was satisfactory and relevant to the topics under investigation. Importantly, students were required to submit 50-word reflections outlining why they felt each video was a worthwhile choice for inclusion in their assignments 


\section{c. Research procedure}

Data was collected from two different sources. First, a questionnaire was distributed to students to gather their views on using video as a source for information in their assignment work, the number of videos they watched, and the quality of the video content. Second, as outlined above, students were asked to complete a 50-word reflective piece for each video used outlining their reasons for choosing that video, using examples of video content if applicable. The reflections provided students with ample opportunity to reflect on their choices. The range of methods employed provided the researcher with interesting data from a variety of sources, while also adding weight and validity to the findings. Out of the 66 students, a total of 61 reflective documents and 31 questionnaires were returned, giving a response rate of $92 \%$ and $47 \%$ respectively.

\section{d. Data analysis}

Data for this study was analysed using the constant comparative method (Glaser and Strauss 1967 in Maykut and Morehouse 1994, 126). This process involved analysing the data for patterns in the keywords and phrases present in student responses. As categories emerged, rules of inclusion were developed to ensure consistency in each category. If a piece of data did not meet the rules for inclusion, a new category was created. This process was repeated until clear categories were present.

In an effort to test the viability and credibility of these categories and the findings within them, the author drew on Guba's (1978, 56-57) work for testing the robustness of qualitative data. First, data was checked for internal and external plausibility, ensuring consistency within categories and cohesion among separate categories. Second, the data was checked to ensure it was inclusive of the data and information that was available for study. Third, data was tested to establish connections to previous work in the field, and its contribution to this enquiry. Finally, a detailed record of the analysis, coding, categorising and presentation of data was kept so that the data was reproducible by another competent judge.

\section{Findings and discussions}

Key themes and findings are now presented using qualitative and quantitative data from questionnaires and student reflections, followed by overall conclusions and recommendations. Data obtained through questionnaires revealed that students' learning experience in using online video as part of their assignments was predominantly positive. $94 \%$ of respondents said that the experience was 'good' or higher. Students found that using video helped them to understand topics $(41 \%)$, offered a multi-modal approach to the assignment $(33 \%)$, and provided them with engaging content (24\%). Students also seemed to engage with a significant amount of content, with $91 \%$ watching five or more videos, $19 \%$ watching $8-10$ videos and $22 \%$ watching $10-12$ videos, before making their selections (Fig. 1). A key contribution of this study is progressing our understanding of how students evaluate and assess digital information in terms of the quality, relevance, and usefulness ( $\mathrm{Ng} \mathrm{2012a)} \mathrm{and} \mathrm{filter} \mathrm{through} \mathrm{this} \mathrm{information} \mathrm{for} \mathrm{its} \mathrm{relevance} \mathrm{to} \mathrm{a}$ given context (Vuorikari et al. 2016). The following sections draw together data on students' reasons for selecting videos for use in their assignments, to gain a better understanding of the factors that influence this process. 


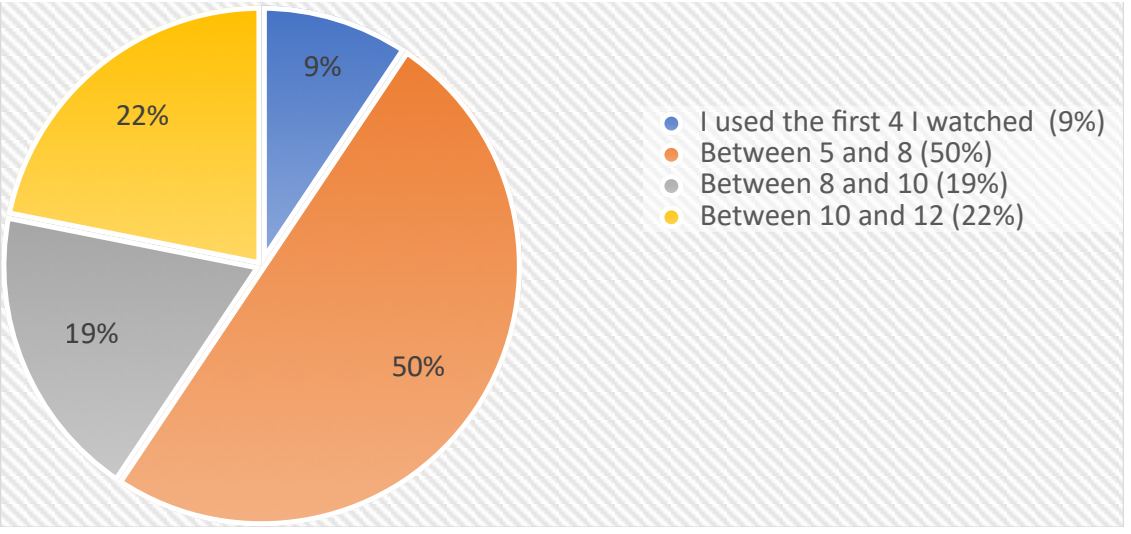

Figure. 1. Number of videos viewed

\section{a. Video was used to support content from lectures and other sources}

Student reflections contained a range of comments indicating that a significant reason for selecting videos was that they supported the development of their topics by confirming, expanding upon, and linking to information they had gained from lectures, reading and other sources (Fig. 2). Comments $(n=259)$ spread across a number of key areas.

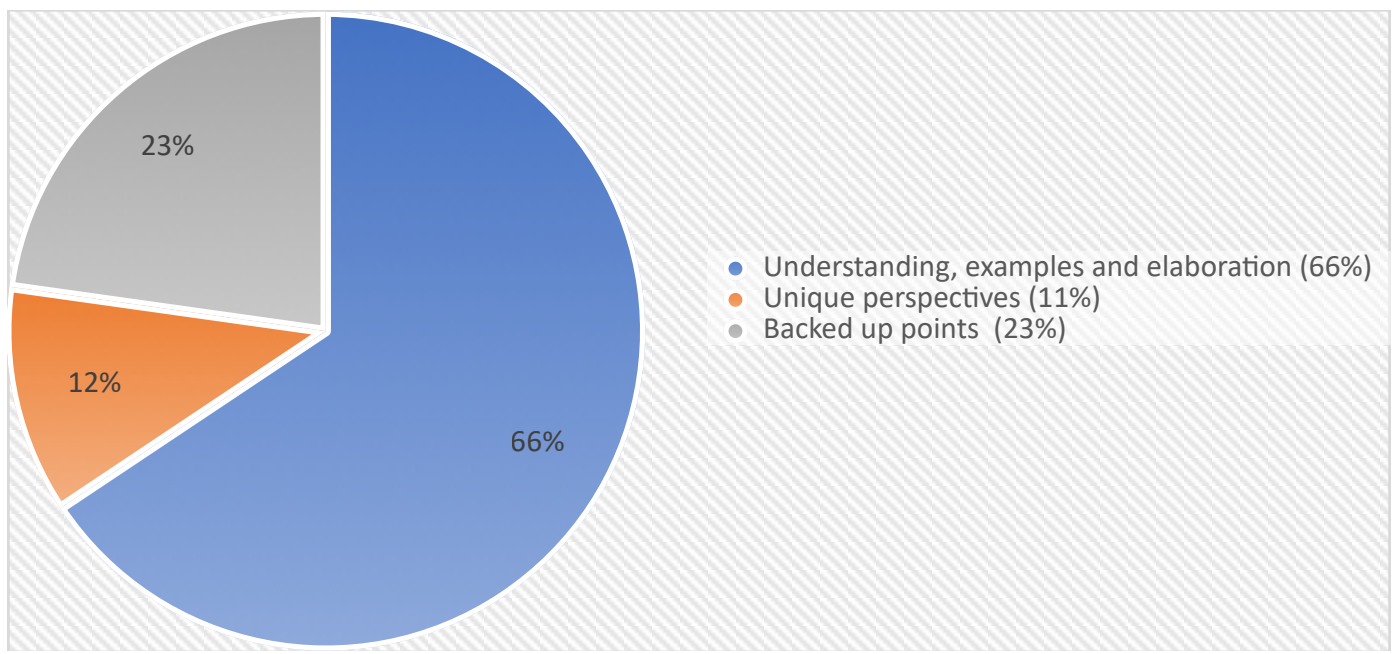

Figure. 2. Criteria for selection A: Support lecture content and other sources

The most prominent of these with 170 comments was that students chose videos for inclusion that confirmed understanding, elaborated on topics, and provided examples to draw upon. In terms of confirming understanding, P1 said the video 'How the communication process works' was helpful as it 'gave me a clear idea of the term encoding that was being used frequently in communications', while P11 selected the video 'Comedy in translation' as it 'explained how and why people are able to learn more from the use of humour in communication'. These comments indicate the potential of video in "adding value through explaining complex processes" (Koumi 2013) and was a key factor in the choices made. Authors such as Srinivasa et al. (2020), Berkhof et al. (2011) and Liu (2011) have suggested that video can enable students to witness the meaning of concepts by providing examples to reinforce learning. This also emerged as a key reason for student selection of video. For example, P14 said that the video 'In the mix - conflict resolution' was helpful in 'seeing how people react to conflict differently', while P22 chose the video 'What is communication' because 'it showed the different ways we use interpersonal skills in our everyday lives by doing simple gestures, non-verbal gestures and using signs and symbols which help us communicate better'. Students also selected videos which allowed them to build on 
existing knowledge (Mitra et al. 2010) and branch off in related directions. For example, P17 used the video 'Greek and Roman Rhetorica' as it 'gave me an insight into how current communication theory is linked to Greek and Roman times', while P15 commented that the video 'Effective listening skills' gave her 'a new and different insight into listening' as it explained that 'listening isn't all about hearing what the person is saying but it's about engaging with them and responding to what they say'.

In a related area, students' reflections also revealed that videos were chosen which offered unique perspectives (Moskovich and Sharf 2012) on topics. These comments $(n=30)$ concentrated on the alternative opinions and contexts students could draw upon. 17 comments related to alternative opinions which helped them to understand the different perspectives related to their topics (Hakkarainen et al. 2007). P6 in his discussion on the process of communication said that he chose the video 'Effective communication skills - monologue vs dialogue' because 'the woman makes her point on how communication should be carried out, it's good to have different opinions heard before getting to make your own call on it'. P37, in her discussion on listening skills, said that the video ' 5 ways to listen better' encouraged her to 'look at listening in a different way than I previously thought and made the reality of it seem more like a task'. Students also made a number of comments $(n=13)$ on the benefit of "showing or documenting phenomena that would otherwise be inaccessible" (Koumi 2013, 32) by viewing the different contexts in which communication skills apply. For example, P28 said that he chose the video 'Connected but alone' as it gave an 'interesting insight into where the world is going with technology and how it can affect our communication skills'. Similarly, P44 used the video 'Intercultural communication' as it 'shows how in different countries their culture influenced their tone of voice and body movement'.

The second most prominent theme with 59 comments, highlighted the importance of linking strategies when incorporating online video into assessment work. Students commented $(n=35)$ that they chose video content which linked to their existing knowledge (Mitra et al. 2010; Jonassen 2000), using it to back up points being made. For example, P5, when writing about barriers to communication, used the video 'How the communication process works' as 'in this video segment they talk about how you should effectively communicate and what you should consider when communicating. Similar to when I mention the example about primary school and know their capacity for language'. P9, when speaking about body language used the video 'Learn the body language' as 'I was backing up my point about how visual communication is very important by using body language, how we convey a message more by use of gestures and movement'. MacKinnon and Vibert (2012) found that the benefit of including video as part of the content offering was especially apparent when linked to existing lecture topics and other sources. Students' selection of online video for their assignments was also linked to these areas, with students choosing videos that linked to other sources of information they had found, corroborating information, and providing additional depth to their topics. For example, P19, when discussing barriers to communication, chose the video 'How the communication process works' because 'it aligned with the knowledge I had previously gained about what the communication process entailed. It also had some cross-over with information we had been presented in lectures'. Similarly, P55 chose the video 'Talk nerdy to $\mathrm{me}^{\prime}$ because 'her opinions on why jargon was a barrier also matched well with other studies I had researched, so her statements were not uncommon'. P35 said that she chose the video 'The communication process' because the 'points are very similar to the academic books I've read'.

This data suggests that when online video is linked to the overall learning objectives and students are encouraged to integrate content into their work (Churchill 2020; Bhatt et al. 2015; Moskovich and Shart 2012; Berk 2009), the filtering strategies adopted are heavily influenced by the

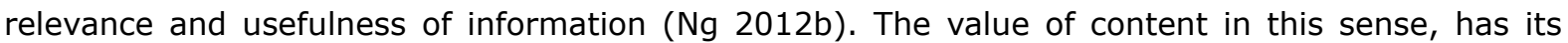
roots in traditional academic information, where these foundations are expanded by contextually relevant content (Berk 2009; Mitra et al. 2010) which builds upon students' existing knowledge, related sources (MacKinnon and Vibert 2012) and is relevant to the instructional goal (Mitra et al. 
2010). Students' use of online video in this manner is significant as it displays 'reproductive literacy' (Eshet-Alkali and Amichai-Hamburger 2004; Eshet-Alkali and Chajut 2009) where online video is combined with existing knowledge to create new interpretations and meanings. Also evident in the selection process is a demonstration of the cognitive and experiential value of video (Koumi 2013) where online video clarified concepts and ideas for students, while also providing them with related contexts and examples to draw upon (Liu 2011).

\section{b. Source and quality of videos}

Student reflections also contained a range of comments indicating that a significant reason for selecting videos stemmed from the quality of the videos and the source from which they came (Fig. 3). Comments ( $n=129)$ spread across a number of key areas.

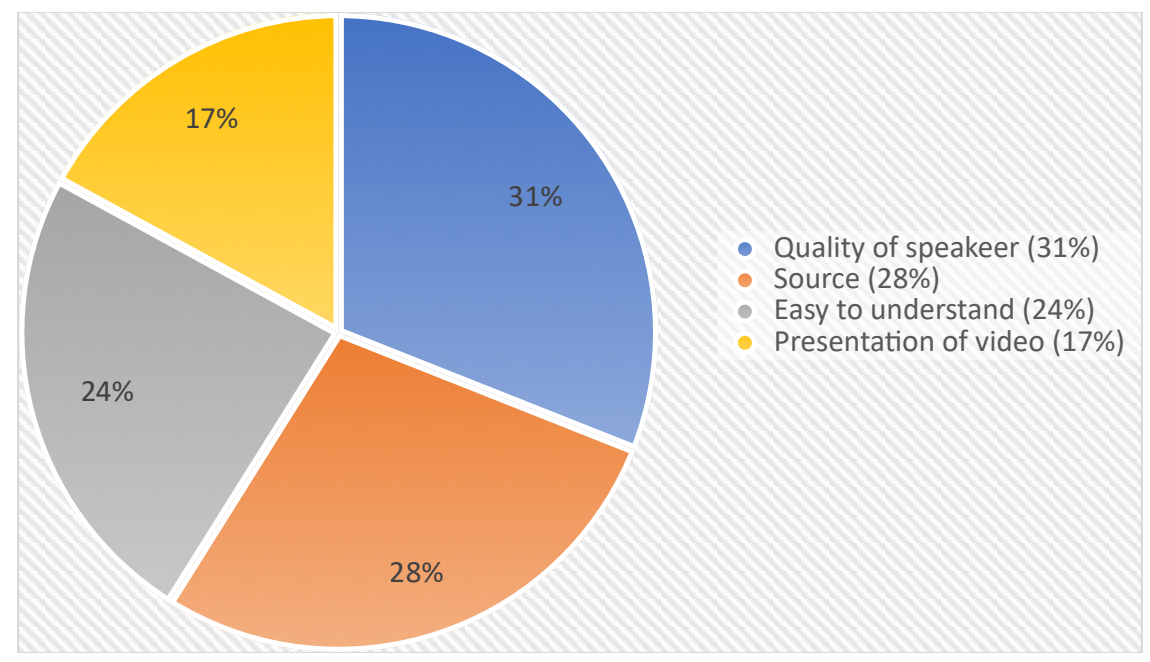

Figure. 3. Criteria for selection B: Source and quality of videos

The most prominent of these with 40 comments, was the quality of the speaker or presenter. Many of the students' commented $(n=21)$ that having access to experts in the field (Mitra et al. 2010; Jonassen 2000) was the reason content was included. Comments in this section indicated that they paid attention to the credentials of the presenters, conducting their own research to gather information. For example, P1 chose the video ' 4 steps to great speaking' to support his assignment topic on vocal skills because 'The speaker in this video, Conor Neill, has been teaching Persuasive Communication on MBA courses for ten years at the IESE Business School, giving this video much credibility in my mind'. Similarly, P24 chose the video 'Understanding body language' for her topic body language because 'I felt the video on Understanding Body Language was a credible source because the woman speaking about body language is a nationally recognized body language expert and has also written many books about the importance of body language'. Students also commented $(n=19)$ that the engaging delivery (Koumi 2013; Mitra et al. 2010) formed part of the decision-making process. For example, P3 chose the video 'The communication process' for her topic on models of communication because 'The speaker conveyed the lesson in a manner that was interesting to listen to'. P8 said that she chose the video 'Killer presentation skills' for her conclusion because 'The speaker is very humorous which makes the idea of public speaking more appealing to me'. Finally, P55 chose the video 'Effective listening skills' for her topic on listening skills because 'the person in this video is confident in what he is saying and his delivery is excellent and engaging'.

The second most prominent area which appeared in students' reflections $(n=36)$ was the source of content, with students paying attention to the video affiliations (Buckingham 2008). For example, using the video 'Talk Nerdy to Me' to support the development of the barriers to communication, P4 said that it was a 'credible resource as it is a TED talk which are talks delivered by professionals who are qualified in their areas'. P10 used the video 'Effective listening skills' for her topic on listening as 'I thought this video was a credible source because at the start of the video it showed 
that it was sponsored by the Royal Bank of Scotland, which is a very recognised bank, and LinkedIn which is a recognised company'. P24 chose the video 'Understanding body language; because she felt that it was a 'credible video source because it was a video from Anderson Coopers show on CNN, which is a credible source for news'.

The final two areas that appeared in students' reflections $(n=53)$, were that students selected content as it was easy to understand and presented information in an engaging way (Bower 2017; Meseguer-Martinez et al. 2017; Koumi 2013). In the first category, students commented $(n=31)$ that the easy to understand nature of the content made it more feasible to incorporate into their work. For example, P8 said that she chose the video 'What is communication' to introduce her essay as 'it explains what communication is in a very simplistic and comprehendible way. It gives us examples of communication e.g. media, gestures and provides us with general information on communication'. P25 selected the video 'Organisational communication' for her topic on the importance of visual communication as 'I felt the video was very informative, factual, easy to follow, interesting and expresses the importance of communication'. In her discussion on models of communication, P60 chose the video 'What is communication' as it 'clearly and simply explains the various forms and channels of communication'. In the second category comments $(n=22)$ indicated that the visual nature and structure of content were important criteria for selection. For example, P3 commented that she chose the video 'What is communication' as the 'use of drawings and animations caught my eye and helped me understand the concept of communication in terms of academic study'. P21 said the video 'What is organisational communication' she selected was 'very appealing to me as the content consisted of pictures rather than someone orating information into the camera'. P57 said that she selected the video 'How the communication process works' for her topic on the models of communication because it helped her to 'understand the models of communication by using simplistic diagrams'.

Data in this theme suggests that when online video is linked to the overall learning objectives and students are encouraged to integrate content into their work (Bhatt et al. 2015; Moskovich and Sharf 2012; Berk 2009), the filtering strategies adopted are also influenced by the quality of the content, both in terms of the credentials of the speakers (Mitra et al. 2010; Jonassen 2000) and their ability to deliver content in an engaging manner. In this sense, the process of integrating

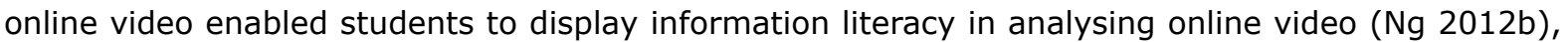
while also confirming the importance of providing students with engaging content that sparked interest and increased motivation to learn (Koumi 2013; Mitra et al. 2010). The data also reveals that while not top of students' lists of criteria, the source of the content also had an impact on the students' decision-making process. Content which comes from a recognisable source, gives credence to the information, and suggests to students that content is reliable and worthwhile. Here we can see elements of media literacy at play (Buckingham 2008), where students have an awareness of the sources of information and are cognisant of the importance of understanding where information comes from. However, questions remain as to whether students automatically trust information simply because it has come from a recognised source. Given the subject matter and that content was selected for students in this research, the impact of this area of data is reduced and would require a different approach to further draw out these findings. Finally, this data confirms that the presentation of the video content and its ability to explain concepts in an easy to understand way have an impact on students' decisions to incorporate online video into their assignments. 


\section{Conclusions and recommendations}

Findings from this study were broken presented in two broad themes: students' selection of online video based on how it supports content from lectures and other sources; and selection of video based on its quality and source. In the first theme, findings indicate that students selected video based on how it supported and developed themes already covered in lectures and other sources. Students chose content that linked to existing topics, confirmed their understanding of topics, built on existing knowledge, and provided examples and alternative perspectives to develop their points. This suggests that when encouraged to reflect on the process of incorporating online video, students use content to display 'reproductive literacy' by weaving online video together with existing information and knowledge acquired through lectures, to create new meanings and understandings. In the second theme, findings indicated that the quality of content, and its source, were also important factors in the selection process. Students chose content based on the quality of the presenter, in terms of their expertise in the field, the quality of the delivery and their affiliations with credible organisations. Also evident was students' choice of video based on the ease of understanding and the visual nature of the content.

This study has shown that when asked to integrate online video into their work, and encouraged to reflect on their choices, students are most concerned with how content can be used to develop and support their arguments. Students evaluate content in terms of its usefulness for the task at hand, selecting online video based on its usefulness to the work being completed. This signifies the importance of curation of content on the part of lecturers, finding and making available content that clearly links to the topics at hand. However, it also suggests that the value in providing video content from a variety of sources lies in its ability not only to confirm what students already know, but allows them to incorporate different opinions, perspectives and points of view which may otherwise be unavailable to them. The quality of online video was also significant, again providing guidance for educators working in this area. In order to encourage students to integrate online video into their work, video should be engaging, explain concepts clearly and hold students' attention. Finding large libraries of video of this kind may still be a challenge into the future, however, a focus on quality over quantity may be the best approach. Students seem clearly aware of the importance of the source of information, both in terms of the credibility of speakers and affiliations associated with online video. This is encouraging in that it demonstrates a clear distinction between recreational use of online video and its application to assignment work.

\section{Limitations}

This study was conducted with a cohort of university students taking part in the B.Sc. in Education and Training, with a sample size of 66 students. The intention was to conduct an in-depth pragmatic study of how students evaluate online video for use in assignments. However, larger scale studies may be needed if definitive claims are to be made about evaluation strategies adopted by students. The researchers' teaching area was chosen so that online video could be implemented and evaluated in practice. A wider study with a more diverse range of students from alternative subject disciplines may yield different results and experiences. Video content in this study was provided by the researcher in a central location. Future studies could focus on examining how students source content from a range of online video repositories, locating content based on set criteria. Such studies could further investigate students' ability to identify relevant content and evaluate this in terms of its suitability for inclusion in their work, biases, and credibility. Finally, academic literature on how students evaluate online video for inclusion in assignment work is uncommon, this means that as research in the area progresses, new alternative themes for study may emerge which were not addressed in this paper. 


\section{References}

Anderson, M. (2015, Feb 12). 5 Facts About Online Video, For YouTube's $10^{\text {th }}$ Birthday. Pew Research Centre. http://www.pewresearch.org/fact-tank/2015/02/12/5-facts- about-onlinevideo-for-youtubes-10th-birthday/.

Bawden, D. (2001). Information and digital literacies: a review of concepts. Journal of documentation, 57(2), 218-259.

Berk, R. A. (2009). Multimedia teaching with video clips: TV, movies, YouTube, and mtvU in the college classroom. International Journal of Technology in Teaching and Learning, 5(1), 1-21.

Berkhof, M., van Rijssen, H. J., Schellart, A. J., Anema, J. R., \& van der Beek, A. J. (2011). Effective training strategies for teaching communication skills to physicians: an overview of systematic reviews. Patient education and counseling, 84(2), 152-162.

Bhatt, I., de Roock, R., \& Adams, J. (2015). Diving deep into digital literacy: emerging methods for research. Language and Education, 29(6), 477-492. https://doi.org/ 10.1080/09500782.2015.1041972

Bohloko, M., Makatjane, T. J., George, M. J., \& Mokuku, T. (2019). Assessing the Effectiveness of using YouTube Videos in Teaching the Chemistry of Group I and VII Elements in a High School in Lesotho. African Journal of Research in Mathematics, Science and Technology Education, 23(1), 75-85.

Bower, M. (2017). Design of technology-enhanced learning; integrating theory and practice. Bingley: Emerald Publishing.

Buckingham, D. (2007). Digital Media Literacies: rethinking media education in the age of the Internet. Research in Comparative and International Education,2(1), 43-55.

Buckingham, D. (2008). Defining digital literacy - what do young people need to know about digital media? In Digital literacies: Concepts, policies and practices, ed. C. Lankshear and M. Knobel, 73?90. New York, Berlin and Oxford: Peter Lang.

Choi, H. J., \& Johnson, S. D. (2010). The effect of context-based video instruction on learning and motivation in online courses. The American Journal of Distance Education, 19(4), 215-227.

Churchill, N. (2020). Development of students' digital literacy skills through digital storytelling with mobile devices. Educational Media International, 57(3), 271-284. https://doi.org/ $10.1080 / 09523987.2020 .1833680$

Dong, C., \& Goh, P. S. (2015). Twelve tips for the effective use of videos in medical education. Medical teacher, 37(2), 140-145.

Eshet-Alkali, Y. E., \& Amichai-Hamburger, Y. (2004). Experiments in digital literacy.CyberPsychology \& Behavior, 7(4), 421-429.

Eshet-Alkalai, Y., \& Chajut, E. (2009). Changes over time in digital literacy. CyberPsychology \& Behavior, 12(6), 713-715.

Gilster, P. (1997). Digital literacy. Wiley Computer Publications.

Guba, E. G. (1978). Toward a Methodology of Naturalistic Inquiry in Educational Evaluation. CSE Monograph Series in Evaluation, 8.

Hakkarainen, P., Saarelainen, T., \& Ruokamo, H. (2007). Towards meaningful learning through digital video supported, case based teaching. Australasian Journal of Educational Technology, 23(1), 87 - 109.

Jonassen, D. H. (2000). Computers as mindtools for schools: Engaging critical thinking. Upper Saddle River, NJ: Prentice-Hall 
JISC. (2015). Building digital capabilities. JISC. Accessed 21st Oct 2020. https:// repository.jisc.ac.uk/6611/1/JFLO0666F_DIGIGAP_MOD_IND_FRAME.PDF

Kettle, M. (2020). How videos are used in secondary school physics teaching. Physics Education, 55(3). https://doi.org/10.1088/1361-6552/ab7084

Kim, K. T. (2019). The structural relationship among digital literacy, learning strategies, and core competencies among south korean college students. Educational Sciences: Theory and Practice, 19(2), 3-21. https://doi.org/10.12738/estp.2019.2.001

Koumi, J. (2013). Designing video and multimedia for open and flexible learning (second edition). Routledge.

Kurtz, G., \& Peled, Y. (2016). Digital Learning Literacies-A Validation Study. Issues in Informing Science \& Information Technology, 13.

Leeds Beckett University. (2014). Embedding digital literacy as a graduate attribute at Leeds Beckett University: Refocusing the Undergraduate Curriculum. Leeds, UK: Beckett University. Retrieved from https://teachlearn.leedsbeckett.ac.uk/-/media/files/clt/ clt_beckett_embedding_digital_literacy_icons.pdf

List, A., Brante, E. W., \& Klee, H. L. (2020). A framework of pre-service teachers' conceptions about digital literacy: Comparing the United States and Sweden. Computers \& Education, 148.

Littlejohn, A., Beetham, H., \& McGill, L. (2012). Learning at the digital frontier: a review of digital literacies in theory and practice. Journal of computer assisted learning, 28(6), 547-556.

Liu, S. H. (2011). Factors related to pedagogical beliefs of teachers and technology integration. Computers \& Education, 56(4), 1012-1022.

MacKinnon, G., \& Vibert, C. (2012). Video databases: An emerging tool in business education. Education and Information Technologies, 19(1), 87-101.

Margaryan, A., Littlejohn, A., \& Vojt, G. (2011). Are digital natives a myth or reality? University students' use of digital technologies. Computers \& Education, 56(2), 429-440.

Martin, A. (2005). DigEuLit-a European framework for digital literacy: a progress report. Journal of eLiteracy, 2(2), 130-136.

Maykut, P., \& Morehouse, R. (1994). Beginning Qualitative Research: A philosophical and practical guide. London: RoutledgeFalmer.

Meseguer-Martinez, A., Ros-Galvez, A., \& Rosa-Garcia, A. (2017). Satisfaction with online teaching videos: A quantitative approach. Innovations in Education and Teaching International, 54(1), 62-67. https://doi.org/10.1080/14703297.2016.1143859

Mitra, B., Lewin-Jones, J., Barrett, H., \& Williamson, S. (2010). The use of video to enable deep learning. Research in Post-Compulsory Education, 15(4), 405-414.

Moskovich, Y., \& Sharf, S. (2012). Using films as a tool for active learning in teaching Sociology. The Journal of Effective Teaching, 12(1), 53-63.

Nagy, J. T. (2018). Evaluation of online video usage and learning satisfaction: An extension of the technology acceptance model. The International Review of Research in Open and Distributed Learning, 19(1).

Ng, W. (2012a). Empowering scientific literacy through digital literacy and multiliteracies. Nova Science Publishers.

Ng, W. (2012b). Can we teach digital natives digital literacy?. Computers \& Education, 59(3), 1065-1078 
Oliver, R., Towers, S., \& Oliver, H. (2000). Information and Communications Technology LiteracyGetting serious about IT. In EdMedia+ Innovate Learning (pp. 862-867). Association for the Advancement of Computing in Education (AACE).

Open University. (2012). Digital and information literacy framework. Milton Keynes, UK: Open University. Retrieved from http://www.open.ac.uk/libraryservices/pages/dilframework/ dilframework_view_by_skill.pdf

Pérez-Escoda, A., García-Ruiz, R., \& Aguaded, I. (2019). Dimensions of digital literacy based on five models of development/Dimensiones de la alfabetización digital a partir de cinco modelos de desarrollo. Cultura y Educación, 31(2), 232-266

Ranga, J. S. (2017). Customized Videos on a YouTube Channel: A beyond the Classroom Teaching and Learning Platform for General Chemistry Courses. Journal of Chemical Education, 94(7), 867-872.

Riismandel, P. (2016, Apr 5). The State of Education Video 2016. Streaming Media. http:// www.streamingmedia. com/Articles/Editorial/Featured-Articles/The-State-of-EducationVideo-2016-110211. Aspx

Rohatgi, A., Scherer, R., \& Hatlevik, O. E. (2016). The role of ICT self-efficacy for students' ICT use and their achievement in a computer and information literacy test. Computers \& Education, 102, 103-116.

Snelson, C. (2008). Web-based video in education: Possibilities and pitfalls. In Proceedings of the Technology, Collages \& Community Worldwide Online Conference (pp. 214-221).

Srinivasa, K., Chen, Y., \& Henning, M. A. (2020). The role of online videos in teaching procedural skills to post-graduate medical learners: A systematic narrative review. Medical Teacher, 1-9.

Sweeney, K., \& Baker, P. (2018). Promoting empathy using video-based teaching. Clinical Teacher, 15(4), 336-340. https://doi.org/10.1111/tct.12693

University of South Australia. (2015). Digital learning strategy 2015-2020. Adelaide, South Australia, 1-13. Retrieved from https://unisa.edu.au/siteassets/about-unisa/docs/digitallearning-strategy.pdf

Vuorikari, R., Punie, Y., Gomez, S. C., \& Van Den Brande, G. (2016). DigComp 2.0: The digital competence framework for citizens. Update phase 1: The conceptual reference model (No. JRC101254). Joint Research Centre (Seville site).

Weeks BK, Horan SA. (2013). A video-based learning activity is effective for preparing physiotherapy students for practical examinations. Physiother. 99(4):292-297 